\title{
Fabrication of highly hydrophilic filter using natural and hydrothermally treated mica nanoparticles for efficient waste oil-water separation
}

Udara Bimendra Gunatilake and Jayasundera Bandara*

National Institute of Fundamental Studies, Hantana Road, CP 20000, Kandy, Sri Lanka

Email: Jayasundera Bandara: bandaraj@ifs.ac.lk; jayasundera@yahoo.com, Tel:+94

812232002

\begin{abstract}
For the effective oil/water separation, a novel superhydrophilic (underwater superoleophobic) filter is fabricated with the naturally and hydrothermally treated mica particles. To fabricate a double layerd filter, hydrothermally treated mica particles were initially electrodeposited on a stainless steel mesh and a natural mica particles were sprayed on the first hydrothermally deposited mica layer. The double layerd mica coated membrane showed superamphiphilic and superhydrophilic/superoleophobic (contact angle $>159^{\circ}$ ) characteristics in air and underwater respectively. The membrane can separate range of oil-water mixtures with oil/water separation efficiency over $~ 99 \%$. Properties of double layered mica membran were investigated and noted that the surface adhesion properties of mica is enhanced by the hydrothermal treatment of mica and the higher roughness of the mica layer is maintained by the natural mica.
\end{abstract}

Keywords: underwater superoleophobicity, mica, oil-water separation, superhydrophilic, super wetting membrane, 


\subsection{Introduction}

In the modern world, water which is one of the scarcest commodities is polluting by several ways in every second. Among the different methods of water pollution, oil spill is one of the major negative contributions to the environment from large number of industries, especially in automobile service stations. (Fried et al., 1979; Mazumder and Mukherjee, 2011) It is known that the prompt water pollution occurs when oil passes in to the water sources, rivers and sea water and the water pollution by oil is considered to be a greater threat to the humans, marine life, animals and to the entire ecosystem. (Fosberg, 1974; Nomack, 2010)In past few decades, the following water treatment techniques have been used; (a) physical treatment methods such as adsorption of dissolved organics on activated carbon, (Gur-Reznik et al., 2008) organoclays, (Doyle and Brown, 2000) copolymers and resins, (Jan and Reed, 1989) sand/stone filters, organics evaporating methods, (Fakhru'l-Razi et al., 2009) electrodialysis methods, (Fakhru'l-Razi et al., 2009) and filtering through oil/water separating membranes, (Kota et al., 2012); (b) chemical/electrochemical treatment methods such as coagulation and flocculation methods,(Bratby, 1980) advanced chemical oxidation methods, (Bautista et al., 2008) electrochemical methods (Ma and Wang, 2006) and photocatalytic treatment methods (Chong et al., 2010; Teng et al., 2015) and (c) biological treatment methods (Fakhru'l-Razi et al., 2009; Sugano et al., 2008; Teng et al., 2015). The major disadvantages of most of these conventional techniques are that these methods are not economical as well as they cannot separate oil/water emulsions efficiently. As a result, the scientists are looking forward to capitalize the cheap and efficient methods to remove oil spills from water.

Contrary to the conventional oil/water separation techniques mentioned earlier, extremely high special wetting solid material surfaces can be used to separate oil and 
water more selectively and easily. (Feng and Jiang, 2006; Li et al., 2016; Sun et al., 2014; Xue et al., 2014) If wetting properties are considered, materials having different affinities towards oil and water would be the best choice for designing of efficient oil/water separation filters. In this respect, materials with both hydrophobic/oleophilic and oleophobic/hydrophilic properties were actuated a broad attention in last few years to invent novel oil/water separation systems. (Bellanger et al., 2014; Darmanin and Guittard, 2014; Xue et al., 2014) However, superhydrophobic materials are unsuitable for the separation of oil/water under gravity due to formation of a water barrier layer on superhydrophobic layer preventing penetration of oils as water has higher density than most of the common oils. (Zhang et al., 2014) On the other hand, underwater superoleophobic and superhydrophilic solid surfaces allow water to penetrate through the membrane while repelling the oil outwards from the membrane allowing separation of oil/water effectively. Going through these theories, various materials such as polyacrylamide hydrogel coated mesh, (Xue et al., 2011) $\mathrm{Cu}(\mathrm{OH})_{2}$ covered mesh, (Liu et al., 2013) photo-induced $\mathrm{TiO}_{2}$ thin films, Sawai et al., 2013) polyelectrolyte/clay hybrid film, (Xu et al., 2013) PANI (Polyaniline) nanowire film, (Ding et al., 2012) polypyrrole nanowire mesh, (Ding et al., 2012) have been fabricated to separate oil/water.

Here, we report the fabrication of a novel superhydrophilic and underwater superoleophobic filter to repel and separate oil under water efficiently by using natural mica mineral particle coated stainless steel mesh. The superhydrophilicity nature and micro hierarchical rough particle layered arrangement of the mica particles leads to enhance the underwater superoleophobicity of the filter. The fabricated filter selectively and effectively repel not only low dense oils but also high dense organic oils from oil/water mixtures such as engine oil, crude oil, gasoline, diesel, vegetable 
oil and forth on. The oil-water separation filter described in this investigation is a low cost method as the main chemical substrate (mica) is taken from a natural source directly. Interestingly, the double layered electrodeposition and spray techniques makes the mica coated mesh more stable under high peeling off forces. Additionally, the cleaning of the mesh is very easy with the help of non-polar solvent at the high contamination levels.

\subsection{Experimental}

2.1 Materials: Stainless steel meshes were purchased from Benny the Stoog, USA. Acetone, sodium hydroxide pellets, absolute ethanol, 1,2-dichloroethane,1-octadecene, hexane, and potassium bromide were purchased from Sigma Aldrich chemicals Pvt. Limited, USA. Silicon oil (commercial grade), kerosene (commercial grade), engine oil (SAE 10W-30), rapeseed oil (commercial grade) was purchased commercially and mica flakes were obtained from mica deposit found in Matale, Sri Lanka.

2.2 Fabrication of Mica coated stainless steel mesh: Natural flake mica (from Matale, Sri Lanka) was finely ground from ring mill crusher and sieved to collect $<50$ $\mu \mathrm{m}$ size mica particles. For electrodeposition of mica, mica particles were hydrothermally treated to make them negatively charged. For hydrothermal treatment, $5.0 \mathrm{~g}$ of mica was stirred with $55.0 \mathrm{ml}$ of $10 \mathrm{M} \mathrm{NaOH}$ for 30 minutes and the mixture was transferred to a $73.0 \mathrm{ml}$ capacity Teflon chamber with a stainless steel hydrothermal vessel and treated at $160^{\circ} \mathrm{C}$ for 12 hours. The highly basic ( $\mathrm{pH} \sim 13$ ) hydrothermally modified mica particles were separated at room temperature by washing with water several times till $\mathrm{pH}$ of the solution reaches $\sim 10.0-11.0$. Stainless steel meshes (\#125/100 micron opening width, size 2”×2”) were ultrasonically cleaned in acetone and then rinsed with ethanol and deionized water. For 
electrodeposition of hydrothermally modified mica, $20 \mathrm{ml}$ of methanol was mixed with $40 \mathrm{ml}$ of hydrothermally modified mica suspension solution. Then two cleaned stainless steel meshes were used as anode and cathode with one inch space difference and $30 \mathrm{~V}$ was supplied for 3 minutes each for both sides of anode mesh. On top of the electrodeposited mica layer, a second mica layer which was prepared by dispersing 1.0 $\mathrm{g}$ of natural mica particles in $30 \mathrm{ml}$ of ethanol followed by ultrasonication (15 minutes) and stirring for 1 hour, was deposited by spray method. Finally, the mesh was sintered at $650^{\circ} \mathrm{C}$ for 1 hour and cooled to room temperature. Finally the mica coated mesh was rinsed with deionized water to remove excess loosely bound mica particles. In this study, three different underwater superoleophobic filters were fabricated; (1) natural mica was sprayed on stainless steel mesh (filter-a), (2) hydrothermally treated mica was electrophoretically deposited on stainless steel mesh (filter-b) and (3) bi-layer filter containing electrophoretic deposited hydrothermally treated mica on stainless steel mesh and sprayed mica layer on the electrodeposited mica layer (filter-c).

2.3 Oil/Water separation Experiments: The oil/water separation apparatus was made by fixing mica coated stainless steel mesh into a PVC union setup. The oil/water mixture was prepared by mixing $10.0 \mathrm{~g}$ of engine oil and $35.0 \mathrm{~g}$ of water. The mica mesh was pre-wetted with water and the water/oil mixture $(3.5: 1 \mathrm{w} / \mathrm{w})$ was poured to the filtration set up (1.0 inch diameter filtering area) at the rate of $1.5 \mathrm{ml} / \mathrm{s}$ under the gravity. Water was collected by a beaker under the PVC union setup. To check the stability of the mesh, the filtration was done continuously for several days. After every filtration step, the mica mesh was rinsed by distilled water to remove the trapped oil droplets from the mesh. The separation efficiency was calculated by $\vartheta=\frac{m \text { remains }}{m \text { initial }} \times 100 \%$ where, $m_{\text {remains }}$ and $m_{\text {initial }}$ is the mass of the oil 
before and after the separation. For the calculation of $m$ remain in the filter, oil remain in the filter was collected to a beaker and the oil residues on the column was wiped with a solvent carefully and weight of the oil was taken after evaporation of the solvent. This procedure was repeated for several oils to get the efficiency of each and the recycle efficiency was checked for 20 cycles with engine oil (SAE 10W-30).

2.4 Instrumentation and characterization: Scanning electron microscope (SEM) images and EDX were taken by Carl Zeiss EVO LS15 scanning electron microscope, Fourier transform infrared spectroscopy (FTIR) was recorded from Thermo Nicolet 6700 FTIR machine. Contact angle images were captured from 8-megapixel iSight camera and contact angles were measured using simple geometric angle measuring Protractor. Crystallographic data was taken from Ultima IV x-ray diffractometer.

\subsection{Results and discussion}

\subsection{Characterization of natural and hydrothermally modified mica}

Mica is a phyllosilicates mineral which forms as layer silicates comprising of Si-AlO tetrahedral sheets between $\mathrm{M}-\mathrm{O}$ and $\mathrm{OH}$ octahedral sheets, where $\mathrm{M}$ is usually $\mathrm{Al}^{3+}$, $\mathrm{Fe}^{2+}, \mathrm{Fe}^{3+}$ or $\mathrm{Mg}^{2+}$. It mostly exists as Biotite $\mathrm{K}(\mathrm{Mg}, \mathrm{Fe})_{3}\left(\mathrm{AlSi}_{3} \mathrm{O}_{10}\right)(\mathrm{OH})_{2}$, Lepidolite $\mathrm{K}(\mathrm{Li}, \mathrm{Al})_{3}\left(\mathrm{AlSi}_{3} \mathrm{O}_{10}\right)(\mathrm{O}, \mathrm{OH}, \mathrm{F})_{2}$, Phlogopite $\mathrm{KMg}_{3}\left(\mathrm{AlSi}_{3} \mathrm{O}_{10}\right)(\mathrm{OH})_{2}$ and Muscovite $\mathrm{KAl}_{2}\left(\mathrm{AlSi}_{3} \mathrm{O}_{10}\right)(\mathrm{OH})_{2}$ structures. (Laoot et al., 2011; Rickwood, 1981) High in silica, the mica group sheet silicate minerals include several closely related materials having nearly perfect basal cleavage which can be split or delaminated into thin sheets usually causing foliation in rocks. Mica is a lightweight mineral having dielectric and hydrophilic characteristics. More importantly, mica is chemically inert material andcan resist nearly all mediums like chemicals, acids, gasses, alkalis and oils which 
makes it an ideal material for the fabrication of oil-water separation filters. (Christenson, 1993)

Strong bonding between mica and steel mesh is a prerequisite for the fabrication of durable filter for the separation of water and oil. However, it was noticed that a filter made of natural mica by spraying method is not long-lasting as mica particles get detached easily from the mesh after very few separation cycles. To overcome this problem, electrophoretic deposition method is employed. As natural mica particles cannot be electrophoretically deposited on steel mesh due to its dielectric nature, hydrothermal treatment with $\mathrm{NaOH}_{(\mathrm{aq})}$ is an essential step to obtain a fine suspension of mica particles at the $\mathrm{pH}$ of 10.0-11.0 with a net negative surface charge on mica particles. Hydrothermally treated mica particles can be easily electrodeposited on steel mesh with strong bonding between mica and the mesh.

\subsubsection{XRD Analysis}

X-ray diffraction patterns of natural mica, natural mica heated at $650{ }^{\circ} \mathrm{C}$, hydrothermally treated mica and hydrothermally treated mica heated at $650^{\circ} \mathrm{C}$ are shown in Figure 1 . As shown in Figure 1a, the natural mica contains mainly Vermiculite $\left[(\mathrm{Mg}, \mathrm{Al})_{3}(\mathrm{Si}, \mathrm{Al})_{4} \mathrm{O}_{10}(\mathrm{OH})_{2} .4 \mathrm{H}_{2} \mathrm{O}\right]$ and Plogophite $\left[\mathrm{KMg}_{3}\left(\mathrm{Si}_{3} \mathrm{Al}\right) \mathrm{O}_{10}(\mathrm{OH})_{2}\right]$ forms of mica.

The characteristic diffractions peaks of Vermiculite at $6.1^{0}(\mathrm{~d}=14.4773), \quad 31.1^{0}$ ( $d=2.8788), 24.8^{0}(d=3.5986), 37.5^{0}(d=2.3964), 18.43^{0}(d=4.8014), 35.2^{0}(d=2.5542), 60.2^{0}$ $(\mathrm{d}=1.5356), \quad(\mathrm{d}=4.6136), 54.6^{0}(\mathrm{~d}=1.6768)$ and $12.4^{0}(\mathrm{~d}=7.1582)$ [JCPDS 340166, JCPDS 760847] are clearly distinguishable in Figure 1a. Also diffraction patterns at $8.8^{0}(\mathrm{~d}=$ 10.1185), $26.4^{0}(\mathrm{~d}=3.3647), 54.8^{0} \quad(\mathrm{~d}=1.6770), 33.9^{0}(\mathrm{~d}=2.622), 60.0^{0}(\mathrm{~d}=1.537)$ and $54.5^{0}$ (d=1.6784) [JCPDS 100493] are due to Plogophiteforms of mica. These results confirm that the mica contains mainly Vermiculite and Plogophite structures. Also, other forms of 
mica such as Lepidolite and Zinnwaldite are absent in mica used in this investigation. When the natural mica is hydrothermally treated with $\mathrm{NaOH}$, Vermiculite and Plogophite forms of natural mica is converted to Clinochlore $\left[(\mathrm{Mg}, \mathrm{Al})_{6}(\mathrm{Al}, \mathrm{Si})_{4} \mathrm{O}_{10}(\mathrm{OH})_{8}\right]$ and Saponite $\left[\mathrm{Na}_{0.33}\right.$ $\left.\mathrm{Mg}_{3.00}\left(\mathrm{Al}_{0.33} \mathrm{Si}_{3.67}\right) \mathrm{O}_{10}(\mathrm{OH})_{2}\right]$ crystal structures as evidenced by the diffraction patterns of hydrothermally treated mica particles shown in Figure 1c. The X-ray diffraction patterns of hydrothermally treated mica which is shown in Figure 1c matched well with the Clinochlore diffraction peaks at $6.2^{0} \quad(\mathrm{~d}=14.3763), 24.5^{0} \quad(\mathrm{~d}=3.6243), 12.2^{0} \quad(\mathrm{~d}=7.2210), 18.2^{0}$ $(d=4.8301), \quad 19.0^{0} \quad(d=4.6264), 30.9^{0} \quad(d=2.9143), 59.7^{0} \quad(d=1.5454), 44.5^{0} \quad(d=2.0488)$ [JCPDS 100183] and Saponite diffraction peaks at $6.9^{0}(\mathrm{~d}=12.7696), 19.2^{0}(\mathrm{~d}=4.5958), 33.9^{0}$ (d=2.6378) ) [JCPDS 120157] indicating that when the natural mica is hydrothermally treated at $150{ }^{\circ} \mathrm{C}$ for 12 hours, natural mica is converted to Clinochlore and Saponite. The Clinochlore crystal structure is one of the most hydrophilic forms of mica structures which contained eighthydroxyl groups compared to two hydroxyl group in Vermiculite and Plogophite. (Wong-Ng et al., 1983)

In the process of fabricating mica layer on stainless steel mesh, mica coated mesh was subjected to heating to enhance the adherence properties of mica on mesh. The X-ray diffraction patterns of heat treated natural mica and hydrothermally treated mica are shown in Figure $1 \mathrm{~b}$ and $1 \mathrm{~d}$ respectively. After heat treatment at $650^{\circ} \mathrm{C}$, natural mica containing Vermiculite is converted to Pyrophyllite $\left[\mathrm{Al}_{2} \mathrm{Si}_{4} \mathrm{O}_{10}(\mathrm{OH})_{2}\right]$ and Talc $\left[\mathrm{Mg}_{3} \mathrm{Si}_{4} \mathrm{O}_{10}(\mathrm{OH})_{2}\right]$ where diffraction peaks seen at $9.6^{0}(\mathrm{~d}=9.1674), 29.4^{0}(\mathrm{~d}=3.0325), 19.3^{0}(\mathrm{~d}=4.5671), 26.6^{0}$ (d=3.3459), 55.9 $(\mathrm{d}=1.644)$ [JCPDS 020613)] matched with Pyrophyllite while the peaks appear at $19.5^{0}(\mathrm{~d}=4.5556), \quad 34.5^{0}(\mathrm{~d}=2.5964), 36.3^{0}(\mathrm{~d}=2.4777), 41.05^{0}(\mathrm{~d}=2.1994), 43.1^{0}$ (d=2.0925), $60.5^{0}(\mathrm{~d}=1.5230)$ [JCPDS 030887] matched well with Talc form. Also, hydrothermally treated mica containing Clinochlore form is converted to Hydrogen Aluminum Silicate $\left[\mathrm{H}_{0.32} \mathrm{Al}_{0.32} \mathrm{Si}_{95.68} \mathrm{O}_{192}\right]$, \{peaks at $8.0^{0}(\mathrm{~d}=11.0454), 8^{0}(\mathrm{~d}=9.8866)$, 
$23.0^{0}(\mathrm{~d}=3.8584), 14.0^{0}(\mathrm{~d}=6.3355)$ [JCPDS 420024] matched with to Hydrogen Aluminum Silicate\}, Talc $\left[\mathrm{Mg}_{3} \mathrm{Si}_{4} \mathrm{O}_{10}(\mathrm{OH})_{2}\right]$ [JCPDS 030887] and Saponite $\left[\mathrm{Na}_{0.33} \mathrm{Mg}_{3.00}\left(\mathrm{Al}_{0.33} \mathrm{Si}_{3.67}\right)\right.$ $\mathrm{O}_{10}(\mathrm{O} \mathrm{H})_{2}$ ] forms.(Wong-Ng et al., 1983)

\subsubsection{FTIR Analysis}

Surface bonding properties of natural and hydrothermally treated mica particles were characterized by FTIR analysis. In Figure 2, the FTIR spectra of natural, hydrothermally treated and sintered mica particles are shown by finger patterns of a, b and c respectively. As shown in Figure 2, some significant changes in surface properties ofnatural, hydrothermally treated and sintered mica particles can be observed. In FTIR analysis of natural mica, the strong peak observed at $1640 \mathrm{~cm}^{-1}$ is due to-OH bending vibrations while the peak at 3418 $\mathrm{cm}^{-1}$ could be assigned to $-\mathrm{OH}$ stretching vibration and adsorbed $\mathrm{H}-\mathrm{O}-\mathrm{H}$. The other peaks seen at 1400, 1012, 812, 684 and $456 \mathrm{~cm}^{-1}$ can be assigned to K-O or Na-O (vibrational bond), Si-O (stretching vibrational bond), Al-OH (bending vibrational bond), Si-O-Al/Mg (bending vibrational bond ) and Si-O (bending vibrational bond) respectively. As shown in curve a in Figure 2, an additional vibration peak seen at $3702 \mathrm{~cm}^{-1}$ is due to presence of highly crystalline Al-OH in natural mica. (Bishop et al., 2008)

Comparison of FTIR spectra of the hydrothermally modified mica particles and natural mica particles indicates some few changes in hydrothermally treated mica particles. Compared to the natural mica particles, for hydrothermally mica particles, a strong peak at $1427 \mathrm{~cm}^{-1}$ can be observed and it could be due to incensement of K-O or Na-O bonds due to hydrothermal process. Interestingly, after hydrothermal treatment of natural mica, two stretching crystalline $\mathrm{OH}$ peaks at 3475 and $3573 \mathrm{~cm}^{-1}$ were noted and this could be due to the addition of the O-H groups from the hydrothermal process. On the other hand, stretching crystalline $\mathrm{OH}$ peaks observed at 3475 and $3573 \mathrm{~cm}^{-1}$ are characteristic to Clinochlore form 
where it shows broad peaks near (3560-3586 $\left.\mathrm{cm}^{-1}\right)$ and $\left(3400-3436 \mathrm{~cm}^{-1}\right)$ due to the interlayer $\mathrm{OH}$ groups. These results further confirm that the natural mica is converted to Clinochlore form when natural mica is subjected to hydrothermal treatment. Furthermore, enhancement in relative intensities of $\mathrm{OH}$ peaks at 3418 and $1640 \mathrm{~cm}^{-1}$ also can be observed in hydrothermally treated sample compared to natural mica.

Significant changes in surface properties of mica were observed when natural and hydrothermally treated mica were subjected to heat treatment. As shown in Figure 2, curve c, $\mathrm{OH}$ bending and stretching peaks are diminished while crystal Al-OH peak at $3702 \mathrm{~cm}^{-1}$ is absent in $650^{\circ} \mathrm{C}$ heated hydrothermally treated mica particles. Additionally, it can be noted that the intensities of almost all other peaks due Si-O (stretching vibrational bond $\sim 1012$ $\mathrm{cm}^{-1}$ ), $\mathrm{K}-\mathrm{O}$ or Na-O (vibrational bond $\sim 1400 \mathrm{~cm}^{-1}$ ), Si-O (bending vibrational bond $\sim 456$ $\mathrm{cm}^{-1}$ ), Si-O-Al/Mg (bending vibrational bond 684 ) and Al-OH ( bending vibrational bond $\sim 812 \mathrm{~cm}^{-1}$ ) have been reduced significantly due to high temperature treatment. (Corma et al., 1994; Góra-Marek et al., 2005; Handke and Mozgawa, 1993; Laoot et al., 2011; Miller and Wilkins, 1952; Saikia and Parthasarathy, 2010).

\subsubsection{Adhesion test}

The major problem with natural mica is that it does not firmly bind to the stainless steel due to lack of binding sites in both natural mica as well as stainless steel. However, hydrothermally natural mica contains fair amount of binding sites that can be bound to both stainless steel as well as natural mica. This way mica can be firmly bound to stainless steel mesh. However, some loosely bound spray deposited mica particles can be easily detached from the membrane. As mentioned earlier, we employed the electrophoretic deposition method to obtain a strongly bonded and homogeneous hydrothermally treated mica layer on stainless steel mesh. The electrophoertic deposition of mica via electric charge ensures firm 
binding of charged mica particles on the charged stainless steel mesh. The required thickness of the deposited layer was obtained by varying the applied voltage and deposition time. The adhesion property of mica on stainless steel mesh was tested by adhesive tape method and the adhesion properties of different filters made of natural mica, hydrothermally mica and heat treated mica are given in Table S1 in SI. As expected, a higher adhesion property was noticed with the filter made of hydrothermally treated mica compared to sprayed mica filter. The results presented above clearly demonstrate that the enhancement of hydroxyl groups in hydrothermally treated mica particles enhances the adhesion propertyof mica onto steel mesh compared to natural mica.

\subsubsection{Surface morphology characterization}

Surface morphology of natural and hydrothermally treated mica was investigated by SEM. The SEM images of natural and hydrothermally treated mica on steel mesh are shown in Figure $3 \mathrm{a}$ and $\mathrm{b}$ respectively in which natural mica was spray deposited on mesh while hydrothermally treated mica was electrodeposited on mesh. SEM images clearly indicate a higher surface roughness for natural mica compared to hydrothermally treated mica indicating hydrothermal treatment results in smooth surface on mica (For further details, see the SEM images of Figure S1 in SI). However, enhanced surface roughness is a prerequisite for better oil-water separation. Hence to increase the surface roughness of hydrothermally mica, on top of the electrodeposited mica layer, a thin layer of natural mica layer was sprayed. The SEM images of mica layer on electrodeposited mica containing double layered mica coated mesh shown in Figure 3c and the magnified image of natural mica (Figure 3d) clearly demonstrate an enhanced surface roughness for double layered mica filter. Hence, with the additional rough mica layer, contact angle of the oil can be increased under the water and hence enhanced oil water separation can be expected. 


\subsubsection{Wetting behaviour of the membrane}

The wettability of the filter is an important parameter for efficient oil-water separation. The uncoated mesh has a water contact angle of $\sim 96^{\circ}$ in air. The hydrophilicity of mica coated mesh is very high in comparison to the wettability of uncoated stainless steel mesh. Their static contact angles are lying in $0-2^{\circ}$ and after two seconds the droplet almost spreads. When the water droplet is contacted with the filters made of natural mica, hydrothermally treated mica and double layered mica containing both natural and hydrothermally treated mica in air, an instant wetting is noted in all three filters indicating that all the filters made of mica are highly superhydrophilic. As coating of mica on mesh enhances the water wettability greatly, water can be easily seeped down by the filter made of mica. As shown in Figure 4, mica coated mesh exhibits oleophilic property in air with silicon oil and several different other oils also behave in similar manner (Figures not shown). However, oleophilicities of filters made of mica, hydrothermally treated mica and double layered mica containing both natural and hydrothermally treated mica showed slightly different oleophilicity where mica and double layered mica exhibited least and most dynamic oleophobicity respectively as shown in Figure $4 . \quad$ In addition, the observed superhudrophilicty of filter can be understood as follow; The Clinochlore form is converted to Hydrogen Aluminum Silicate, Talc and Saponite after the heat treatment. $\left(650^{\circ} \mathrm{C}\right)$. Dehydroxylation of the hydroxyl groups of the inter layers is possible around $500-600{ }^{\circ} \mathrm{C}$ and the dehydroxylation temperature depends on the particle sizes. After sintered, the dehydroxylated interlayer sheet is divided into areas enriched in $\mathrm{MgO}$ and porous areas with a deficit in MgO. Microspores are then formed in these MgO deficient regions. When the sample comes to room temperature it has ability to absorb water to these microspores enhancing the superhydrophilicity. (Villieras, 1994) 
Figure 5 shows the underwater contact angle of 1,2- dichloroethane with filters a, b, c where the underwater oil wettability of the mesh was evaluated by immersing the mica coated mesh in aqueous media. (filter-a, natural mica was sprayed on stainless steel mesh, filter-b, hydrothermally treated mica was electrophoretically deposited on stainless steel mesh, filter-c bi-layer filter containing electrophoretic deposited hydrothermally treated mica on stainless steel mesh and sprayed mica layer on the electrodeposited mica layer). The estimated underwater contact angels of filters a, b and c with 1,2- dichloroethane are given in Table 1. As given in Table 1, contact angel measurements indicate that all the filters made of mica exhibit underwater oleophobic property allowing separation of oil and water. However, underwater superoleophobic property of all three mica coated meshes varies in the order (a) $>$ (c) $>$ (b) which could be due to the variation of surface roughness of the mica surfaces as shown previously by SEM images. The uncoated stainless steel mesh exhibited underwater oleophilic property with a contact angel of $\sim 68^{\circ}$ with 1,2 - dichloroethane.

According to the static contact angle of the mica surfaces, it can be clearly expressed that the hydrophilic phases of mica in the air is automatically converted to superoleophobic solid surfaces under water. It is known that aluminosilicate mica mineral consists of Al-Si-O tetrahedral sheets sandwiched by Mg, Fe, Li trioctahedral sites and altogether it's surrounded by $\mathrm{OH}$ crystalline bonds. Hence, the atomic composition and arrangement makes mica to possess higher surface energy with compared to other mineral groups. To get a clear logical mechanism of the underwater superoleophobicity of mica particles it should have to consider the theories of Young's equation.(Young, 1805) The contact angle of water $(\theta w)$ and oil $(\theta o)$ in air can be given as,

$$
\cos \theta w=\frac{\gamma s a-\gamma s w}{\gamma w a}(1)
$$


$\cos \theta o=\frac{\gamma s a-\gamma s o}{\gamma o a}(2)$

where, $\gamma s a, \gamma s w, \gamma w a, \gamma s o$ and $\gamma o a$ are the surface tension of solid-air, solid-water, waterair, solid-oil, oil-air interfaces respectively. This Young's equation can be extended to an underwater oil droplets in solid surfaces as oil/water/solid systems. (Cai et al., 2014) In such cases underwater oil contact angle ( $\theta o w)$ can be expressed as,

$$
\begin{aligned}
& \cos \theta o w=\frac{\gamma s w-\gamma s o}{\gamma o w} \\
& \cos \theta o w=\frac{\gamma o a \cos \theta o-\gamma a w \cos \theta w}{\gamma o w}
\end{aligned}
$$

where, $\gamma o a, \gamma s w, \gamma a w, \gamma s o, \gamma o a, \gamma o w$ are the surface tension of oil-air, solid-water, airwater, solid-oil, oil-air and oil-water interfaces respectively. It can be derived that, to be underwater superoleophobic, $\cos \theta o w<0$ which means $\cos \theta w>0$ and $\theta w$ should be lower than $90^{\circ}$. Under such conditions, it can be expected that underwater superoleophobic materials could be hydrophilic in air. According to above verifications, hydrophilic materials in air should be suitable to prepare underwater superoleophobic solid surfaces. (Bellanger et al., 2014; Chen and Xu, 2013; Darmanin and Guittard, 2014; Waghmare et al., 2013). If the same theory is applied to our system, the bare stainless steel mesh should exhibit hydrophobic properties in air (contact angle $\sim 96^{\circ}$ ) and oleophilic (contact angle $\sim 67^{\circ}$ ) properties in under water. Mica coated steel mesh exhibits an underwater oil contact angle of $163^{\circ}$, making the underwater oleophilic bare steel mesh into underwater superoleophobic. Hence, the enhancement of the underwater superoleophobicity is due to the hydrophilicity of mica in air and the micro hierarchical structural behaviour of the coated mica layer which can be behave according to the Cassie Baxter model. (Cassie, 1948; Liu et al., 2009)

\subsubsection{Oil-water separation}


The underwater superoleophobicity filters were tested for the separation of oil and water mixture and the simple water/oil separation setup is illustrated in Figure 6. In assembling the setup, mica coated filter mesh (filter c, \#125 mesh pore size, containing electrodeposited under layer mica and over layer sprayed mica) is fixed in a PVC union joint and a mixture [1:3.5 ratio $(\mathrm{w} / \mathrm{w})]$ of water and commercial engine oil (SAE 10W-30) was passed through the filter. It was observed that the water permeated through the porous membrane without any blockage with the \#125 mesh pore size. The separation of engine oil (yellow-brown colour) and the water (colourless) can be seen visibly in Figure 6 indicating the underwater superoleophobic mesh can effectively separate oil and water without any extra force under gravity. It was noted that at the first separation cycle, it performs $>99 \%$ separation efficiency.

The durability and the separation of different oils of mica coated mesh were tested and the results are shown in Figure $7 \mathrm{a}$ and $\mathrm{b}$ respectively. For durability test, the filter was used for several cycles of oil-water separation and it was noted at each cycle, over 97.5 ( \pm 1.8$) \%$ separation efficiency was achieved where water in the mixture passed through the mesh quickly, and no visible oil was observed in the collected water. Interestingly it was noted that the oil-plugged in the mica coated mesh can be easily be removed by passing through a mixture of water and hexane through filter in air. The oil water separation ability of the filter c, (\#125 mesh pore size) were tested for different oil types as shown in Figure 7b. It was clearly observed an oil water separation efficiency of $\sim 99.9 \%$ for high viscous oil (viscosity > 1 cP) while 90-95\% oil water separation efficiency was observed for low viscous oil (viscosity $<1$ cP)(Genereaux, 1930). The poor oil water separation of low viscous oils in the mesh with \#125 pore size was due to penetration of less viscous oil through the holes of the mesh which can be avoided by using small pore size mesh (i.e.> \#175 pore size mesh). Despite over 99\% water/oil separation could achieve under normal waste oil/water condition, 
99\% water oil separation may not be achieved for waste water containing excess oil due to loss of underwater oleophobicity as a results of lack of water layer. This could be a practical limitation and hence proper designing of the reactor may solve this problem.

\section{Conclusion:}

Underwater superoleophobic nature of natural mica and hydrothermally modified mica was demonstrated by coating mica on stainless steel mesh. Natural mica exhibited enhanced underwater superoleophobic properties but poorly adhere on the steel mesh. An adherence property of mica on steel mesh was improved by hydrothermal treatment of mica and electrophoretic deposition of hydrothermally modified mica on mesh. Hence by using modified and natural mica, a double mica filter was successfully fabricated on steel mesh by maintaining both adherence and underwater superoleophobic nature of mica. The membrane can separate range of oil-water mixtures with oil/water separation efficiency over $\sim 99 \%$ due superamphiphilic and superoleophobic (contact angle $>159^{\circ}$ ) characteristics in air and underwater respectively. The mica coated steel mesh is cheap and easy to handle while it could effectively and separate water from the different oil-water mixtures

\section{Acknowledgements}

This work was financially supported by under the grant of RG/2012/ESA/01, National Science Foundation, Sri Lanka. 


\section{References}

Bautista, P., Mohedano, A., Casas, J., Zazo, J., Rodriguez, J., 2008. An overview of the application of Fenton oxidation to industrial wastewaters treatment. J. Chem. Tech. Biotech. 83, 1323-1338.

Bellanger, H., Darmanin, T., Taffin de Givenchy, E., Guittard, F., 2014. Chemical and physical pathways for the preparation of superoleophobic surfaces and related wetting theories. Chemical reviews 114, 2694-2716.

Bishop, J., Lane, M., Dyar, M., Brown, A., 2008. Reflectance and emission spectroscopy study of four groups of phyllosilicates: Smectites, kaolinite-serpentines, chlorites and micas. Clay Minerals 43, 35-54.

Bratby, J., 1980. Coagulation and flocculation. England: Uplands.

Cai, Y., Lin, L., Xue, Z., Liu, M., Wang, S., Jiang, L., 2014. Filefish-Inspired Surface Design for Anisotropic Underwater Oleophobicity. Adv. Funct. Mater. 24, 809-816.

Cassie, A., 1948. Contact angles. Discuss. Faraday Soc. 3, 11-16.

Chen, P.-C., Xu, Z.-K., 2013. Mineral-coated polymer membranes with superhydrophilicity and underwater superoleophobicity for effective oil/water separation. Sci. Rep. 3.

Chong, M.N., Jin, B., Chow, C.W., Saint, C., 2010. Recent developments in photocatalytic water treatment technology: a review. Water research 44, 2997-3027.

Christenson, H., 1993. Adhesion and surface energy of mica in air and water. The Journal of Physical Chemistry 97, 12034-12041.

Corma, A., Fornes, V., Navarro, M., Perezpariente, J., 1994. Acidity and stability of MCM-41 crystalline aluminosilicates. Journal of Catalysis 148, 569-574.

Darmanin, T., Guittard, F., 2014. Wettability of conducting polymers: From superhydrophilicity to superoleophobicity. Prog. Polym. Sci. 39, 656-682.

Ding, C., Zhu, Y., Liu, M., Feng, L., Wan, M., Jiang, L., 2012. PANI nanowire film with underwater superoleophobicity and potential-modulated tunable adhesion for no loss oil droplet transport. Soft Matter 8, 9064-9068.

Doyle, D., Brown, A., 2000. Produced water treatment and hydrocarbon removal with organoclay, SPE Annual Technical Conference and Exhibition. Society of Petroleum Engineers.

Fakhru'I-Razi, A., Pendashteh, A., Abdullah, L.C., Biak, D.R.A., Madaeni, S.S., Abidin, Z.Z., 2009. Review of technologies for oil and gas produced water treatment. J. Hazard. Mater. $170,530-551$. 
Feng, X., Jiang, L., 2006. Design and creation of superwetting/antiwetting surfaces. Advanced Materials 18, 3063-3078.

Fosberg, T., 1974. Method and apparatus for detecting oil pollution in water. Google Patents.

Fried, J., Muntzer, P., Zilliox, L., 1979. Ground-Water Pollution by Transfer of Oil Hydrocarbons. Groundwater 17, 586-594.

Genereaux, R.P., 1930. Viscosity Data in Graphical Form. Industrial \& Engineering Chemistry $22,1382-1385$.

Góra-Marek, K., Derewiński, M., Sarv, P., Datka, J., 2005. IR and NMR studies of mesoporous alumina and related aluminosilicates. Catalysis today 101, 131-138.

Gur-Reznik, S., Katz, I., Dosoretz, C.G., 2008. Removal of dissolved organic matter by granular-activated carbon adsorption as a pretreatment to reverse osmosis of membrane bioreactor effluents. Water research 42, 1595-1605.

Handke, M., Mozgawa, W., 1993. Vibrational spectroscopy of the amorphous silicates. Vibrational Spectroscopy 5, 75-84.

Jan, R., Reed, T., 1989. New caustic process for softening produced water for steam generation. SOC OF PETROLEUM ENGINEERS OF AIME, RICHARDSON, TX,(USA). 519-525.

Kota, A.K., Kwon, G., Choi, W., Mabry, J.M., Tuteja, A., 2012. Hygro-responsive membranes for effective oil-water separation. Nature communications 3, 1025.

Laoot, P., Rangsriwatananon, K., Chaisena, A., 2011. Synthesis of sodium-type fluorophlogopite mica from perlite and diatomite. J. Ceram. Process. Res 12, 273-278.

Li, H., Zhao, X., Wu, P., Zhang, S., Geng, B., 2016. Facile preparation of superhydrophobic and superoleophilic porous polymer membranes for oil/water separation from a polyarylester polydimethylsiloxane block copolymer. J. Mater. Sci. 51, 3211-3218.

Liu, M., Wang, S., Wei, Z., Song, Y., Jiang, L., 2009. Bioinspired design of a superoleophobic and low adhesive water/solid interface. Advanced Materials 21, 665-669.

Liu, N., Chen, Y., Lu, F., Cao, Y., Xue, Z., Li, K., Feng, L., Wei, Y., 2013. Straightforward oxidation of a copper substrate produces an underwater superoleophobic mesh for oil/water separation. ChemPhysChem 14, 3489-3494.

Ma, H., Wang, B., 2006. Electrochemical pilot-scale plant for oil field produced wastewater by $\mathrm{M} / \mathrm{C} / \mathrm{Fe}$ electrodes for injection. Journal of hazardous materials 132, 237-243.

Mazumder, D., Mukherjee, S., 2011. Treatment of automobile service station wastewater by coagulation and activated sludge process. Int J Environ Sci Dev 2, 64-69. 
Miller, F.A., Wilkins, C.H., 1952. Infrared spectra and characteristic frequencies of inorganic ions. Analytical Chemistry 24, 1253-1294.

Nomack, M., 2010. Environmental impacts of oil spills. Encyclopedia of Earth.

Reed, B.E., Carriere, P., Lin, W., Roark, G., Viadero, R., 1998. Oily wastewater treatment by ultrafiltration: pilot-scale results and full-scale design. Practice Periodical of Hazardous, Toxic, and Radioactive Waste Management 2, 100-107.

Rickwood, P.C., 1981. The largest crystals. American Mineralogist 66, 885-907.

Saikia, B.J., Parthasarathy, G., 2010. Fourier transform infrared spectroscopic characterization of kaolinite from Assam and Meghalaya, Northeastern India. Journal of Modern Physics 1, 206.

Sawai, Y., Nishimoto, S., Kameshima, Y., Fujii, E., Miyake, M., 2013. Photoinduced Underwater Superoleophobicity of TiO2 Thin Films. Langmuir 29, 6784-6789.

Sugano, M., Takagi, H., Hirano, K., Mashimo, K., 2008. Hydrothermal liquefaction of plantation biomass with two kinds of wastewater from paper industry. J. Mater. Sci. 43, 2476-2486.

Sun, H., La, P., Zhu, Z., Liang, W., Yang, B., Zhao, X., Pei, C., Li, A., 2014. Hydrophobic carbon nanotubes for removal of oils and organics from water. J. Mater. Sci. 49, 6855-6861.

Teng, F., Zhang, G., Wang, Y., Gao, C., Zhang, Z., Xie, E., 2015. Photocatalytic properties of titania/porous carbon fibers composites prepared by self-template method. J. Mater. Sci. 50, 2921-2931.

Villieras, F.; Yvon, J.; Cases, J.; De Donato, P.; Lhote, F.; Baeza, R., 1994, Development of microporosity in clinochlore upon heating. Clays Clay Miner. 42, 679-688.

Waghmare, P.R., Das, S., Mitra, S.K., 2013. Under-water superoleophobic Glass: Unexplored role of the surfactant-rich solvent. Scientific reports 3.

Wong-Ng, W., Holomany, M., McClune, W.F., Hubbard, C.R., 1983. The JCPDS Data BasePresent and Future, Adv. X-Ray Anal. Springer, pp. 87-88.

Xu, L.-P., Peng, J., Liu, Y., Wen, Y., Zhang, X., Jiang, L., Wang, S., 2013. Nacre-inspired design of mechanical stable coating with underwater superoleophobicity. ACS nano 7, 5077-5083.

Xue, Z., Cao, Y., Liu, N., Feng, L., Jiang, L., 2014. Special wettable materials for oil/water separation. J. Mater. Chem. A 2, 2445-2460.

Xue, Z., Wang, S., Lin, L., Chen, L., Liu, M., Feng, L., Jiang, L., 2011. A novel superhydrophilic and underwater superoleophobic hydrogel-coated mesh for oil/water separation. Adv. Mater. 23, 4270-4273. 
Young, T., 1805. An essay on the cohesion of fluids. Philosophical Transactions of the Royal Society of London, 65-87.

Zhang, W., Zhu, Y., Liu, X., Wang, D., Li, J., Jiang, L., Jin, J., 2014. Salt-Induced Fabrication of Superhydrophilic and Underwater Superoleophobic PAA-g-PVDF Membranes for Effective Separation of Oil-in-Water Emulsions. Angew. Chem. Int. Ed. 53, 856-860. 


\section{Table caption}

Static contact angles of oil (1.2-dichloroethane) in the medium of water.

Table 1.

\begin{tabular}{|c|c|c|c|c|}
\hline Mesh type & Stainless Steel & $\begin{array}{l}\text { (a) Mica } \\
\text { sprayed } \\
\left(650^{\circ} \mathrm{C}\right)\end{array}$ & $\begin{array}{c}\text { (b) Modified } \\
\text { Mica } \\
\text { electrodepos } \\
\text { ited (650 } \\
\left.{ }^{\circ} \mathrm{C}\right)\end{array}$ & $\begin{array}{l}\text { (c) Both } \\
\text { electrodeposited } \\
\text { and sprayed } \\
\text { layers }\left(650^{\circ} \mathrm{C}\right)\end{array}$ \\
\hline $\begin{array}{l}\text { Contact angle } \\
\text { of oil droplets } \\
\text { in water (deg) }\end{array}$ & $66.8 \pm 4.7$ & $164.7 \pm 2.9$ & $159.5 \pm 2.0$ & $163.0 \pm 1.9$ \\
\hline
\end{tabular}




\section{Figure captions}

Fig. 1: XRD analysis of (a) natural mica (b) natural mica at $650{ }^{\circ} \mathrm{C}$ (c) hydrothermally modified mica (d) hydrothermally modified mica at $650^{\circ} \mathrm{C}$. [Notation- v(Vermiculite), pl( Plogophie), py (Pyrophyllite), $\boldsymbol{t}$ (talc), c (Clinochlore), s (Saponite), a (Hydrogen Aluminum Silicate)]

Fig. 2. (a) FTIR spectra of natural mica particles. (b) FTIR spectra of hydrothermally modified mica particles. (c) FTIR spectra of the $650{ }^{\circ} \mathrm{C}$ sintered mica particles.

Fig. 03. SEM images of low magnification (a) Hydrothermally modified mica electrodeposited mesh, (b) natural mica sprayed mesh, (c) Sprayed layer on top of the electrodeposited layer, (d) 10 kx magnified image of random area of SEM image c.

Fig. 4. Wetting properties of oil (silicon oil) in air [continues images taken within 100 seconds after oil touching to the mesh] (a) sprayed mica mesh (b) electrodeposited mica mesh (c) bi-layer of electrodeposited and sprayed mesh.

Fig. 5. Images of oil droplet (1,2 dichloroethane) under water (a) oil droplet on stainless steel mesh (b) oil droplet on mica sprayed $\left(650{ }^{\circ} \mathrm{C}\right)$ (c) oil droplet on modified mica electrodeposited $\left(650^{\circ} \mathrm{C}\right.$ ) (d) oil droplet on both electrodeposited and sprayed layers (650 $\left.{ }^{\circ} \mathrm{C}\right)$.

Fig. 06. water/oil seperation process (a) complete setup for the separation (mesh fixed inside the union) (b,c) oil/water separation process (d) separated oil and water (right side - oil, left side - water).

Fig. 07. (a) Recycling ability of the mica coated mesh, (b) separation efficiency of the different oils. 


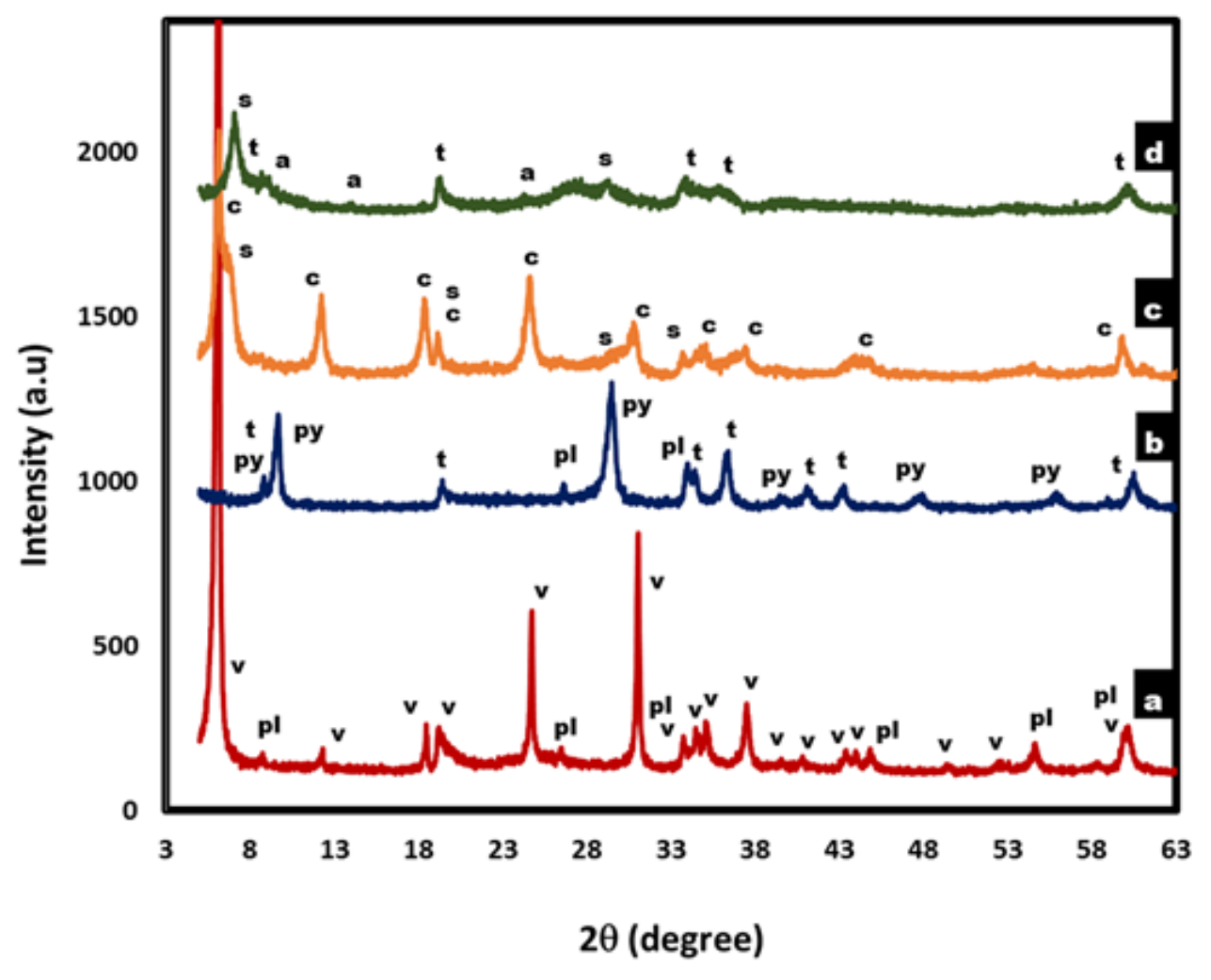

Figure 1 


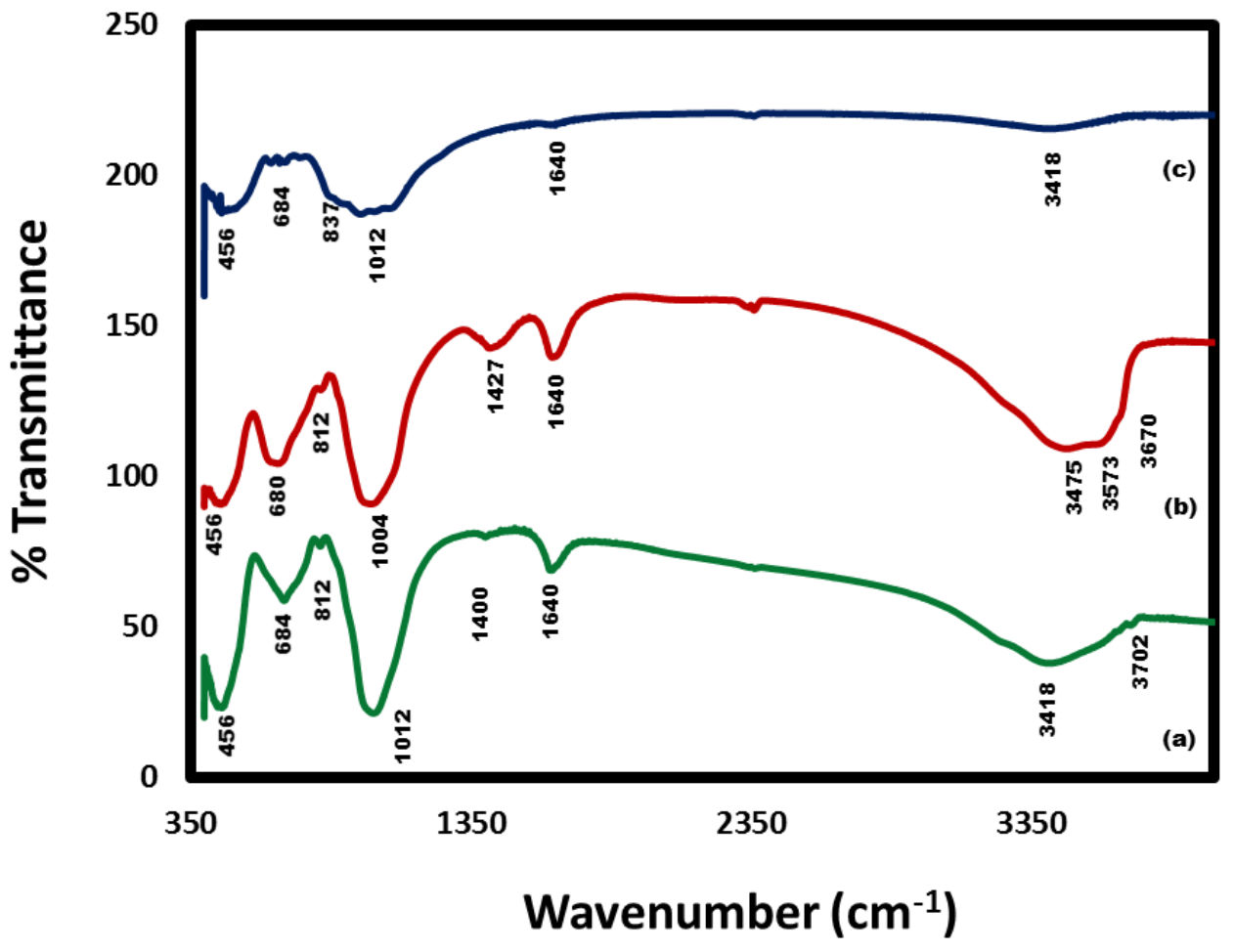

Figure 2 


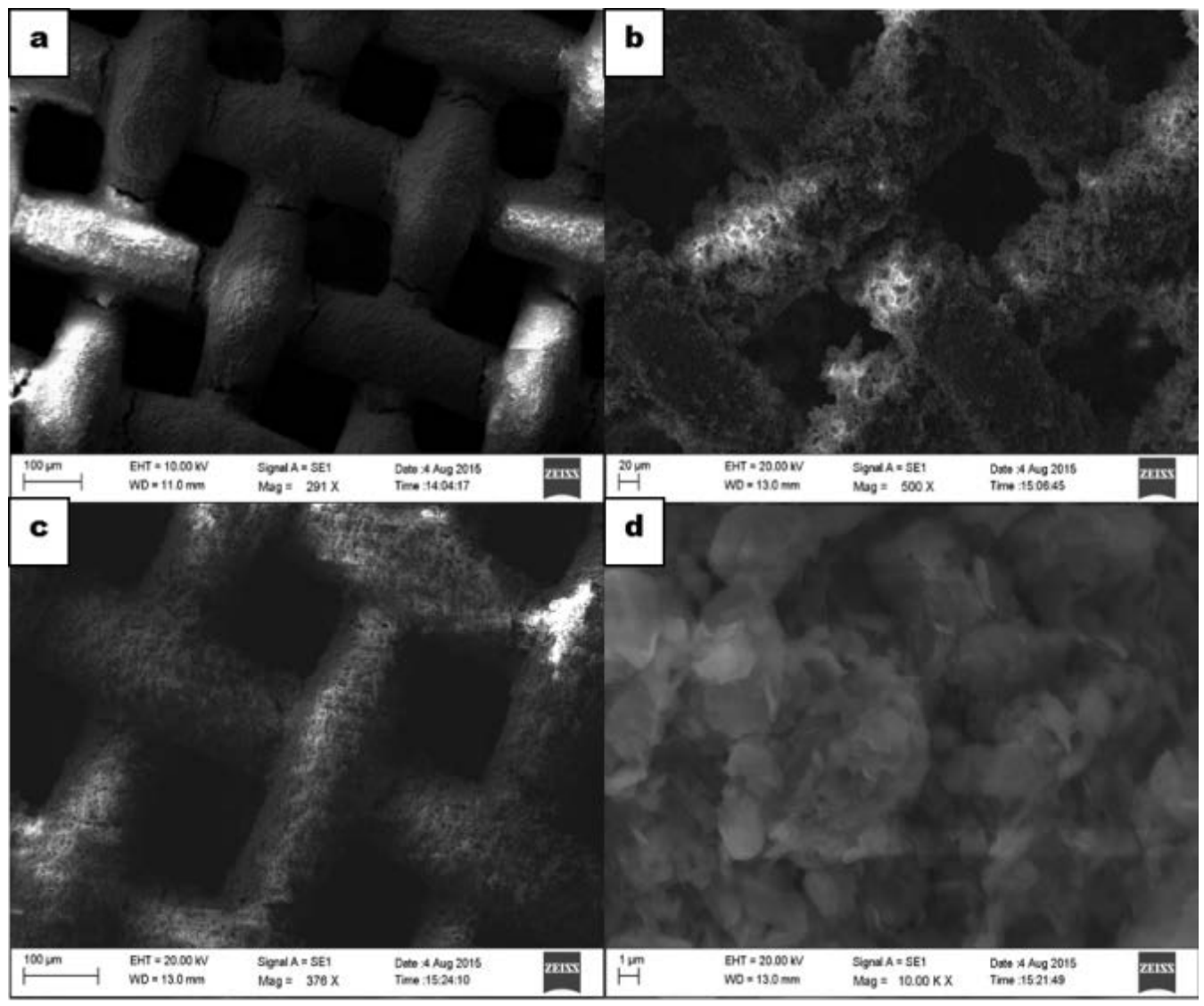

Figure 03 


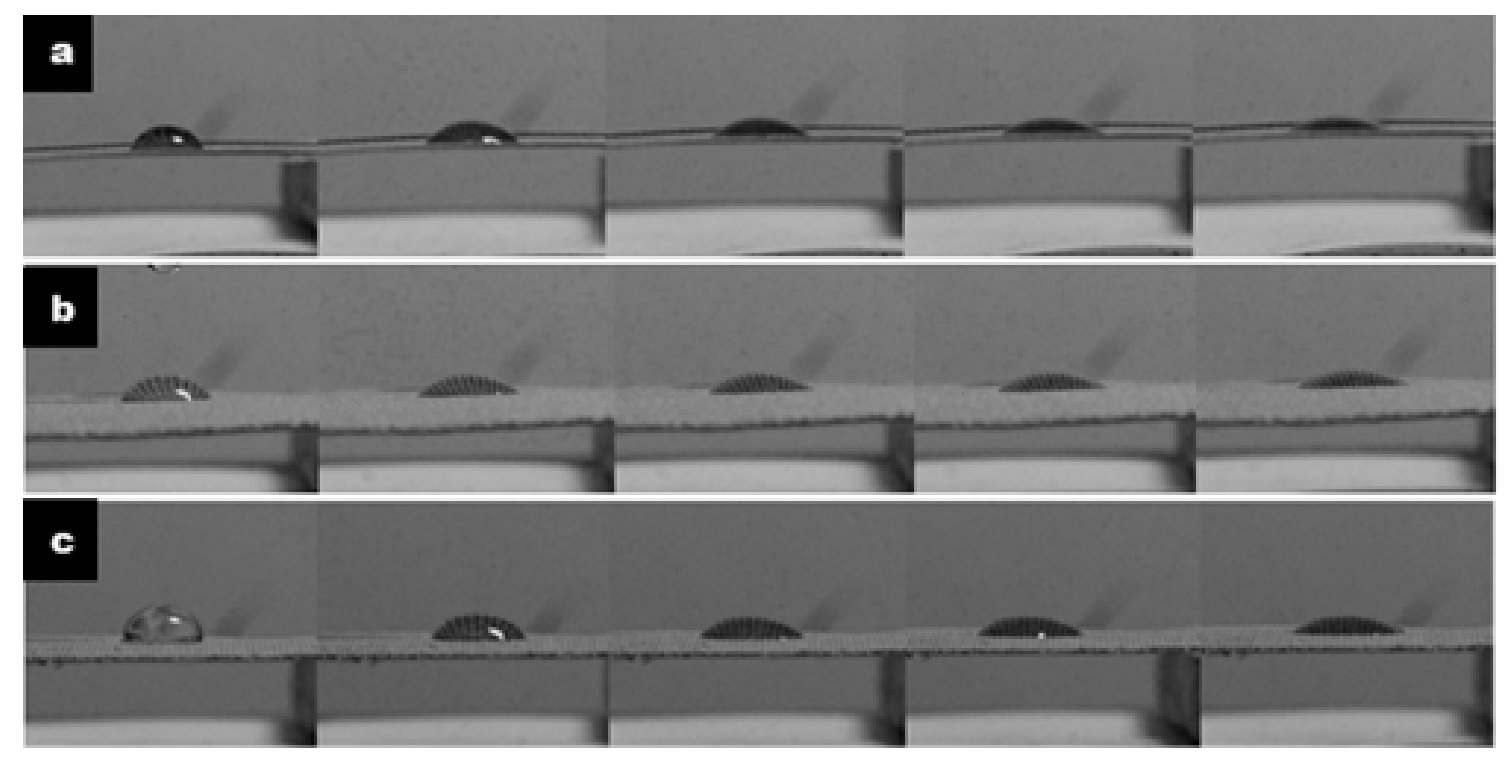

Figure 4 


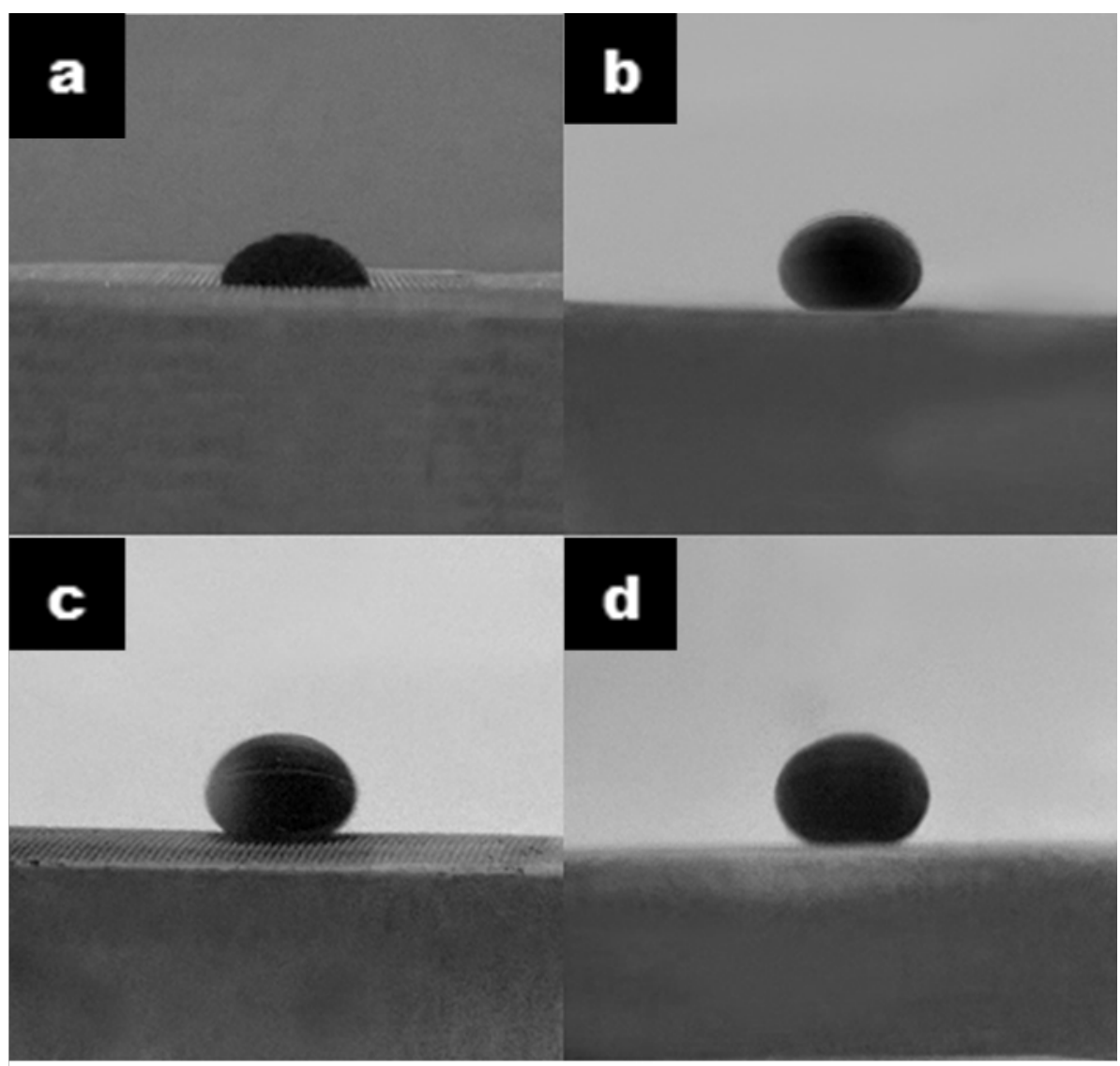

Figure 5 


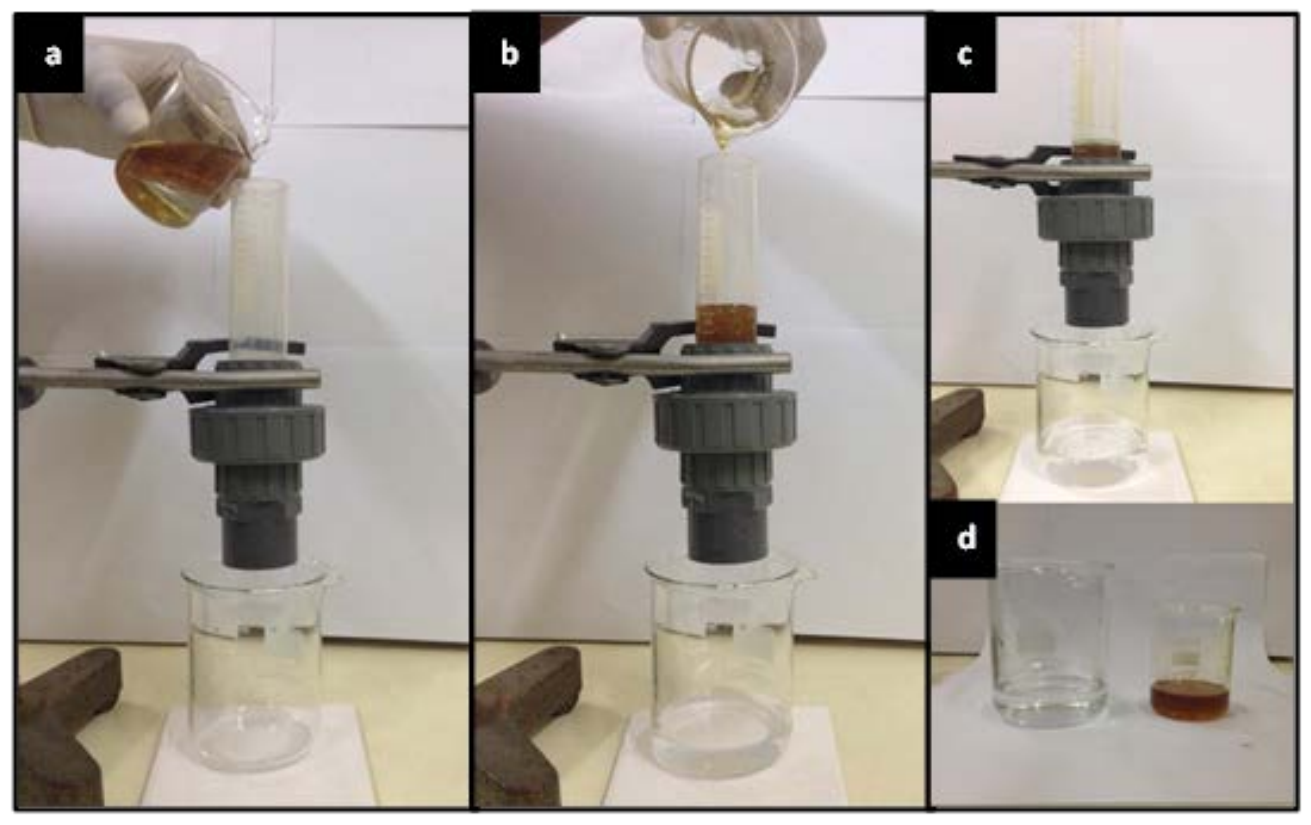

Figure 06 

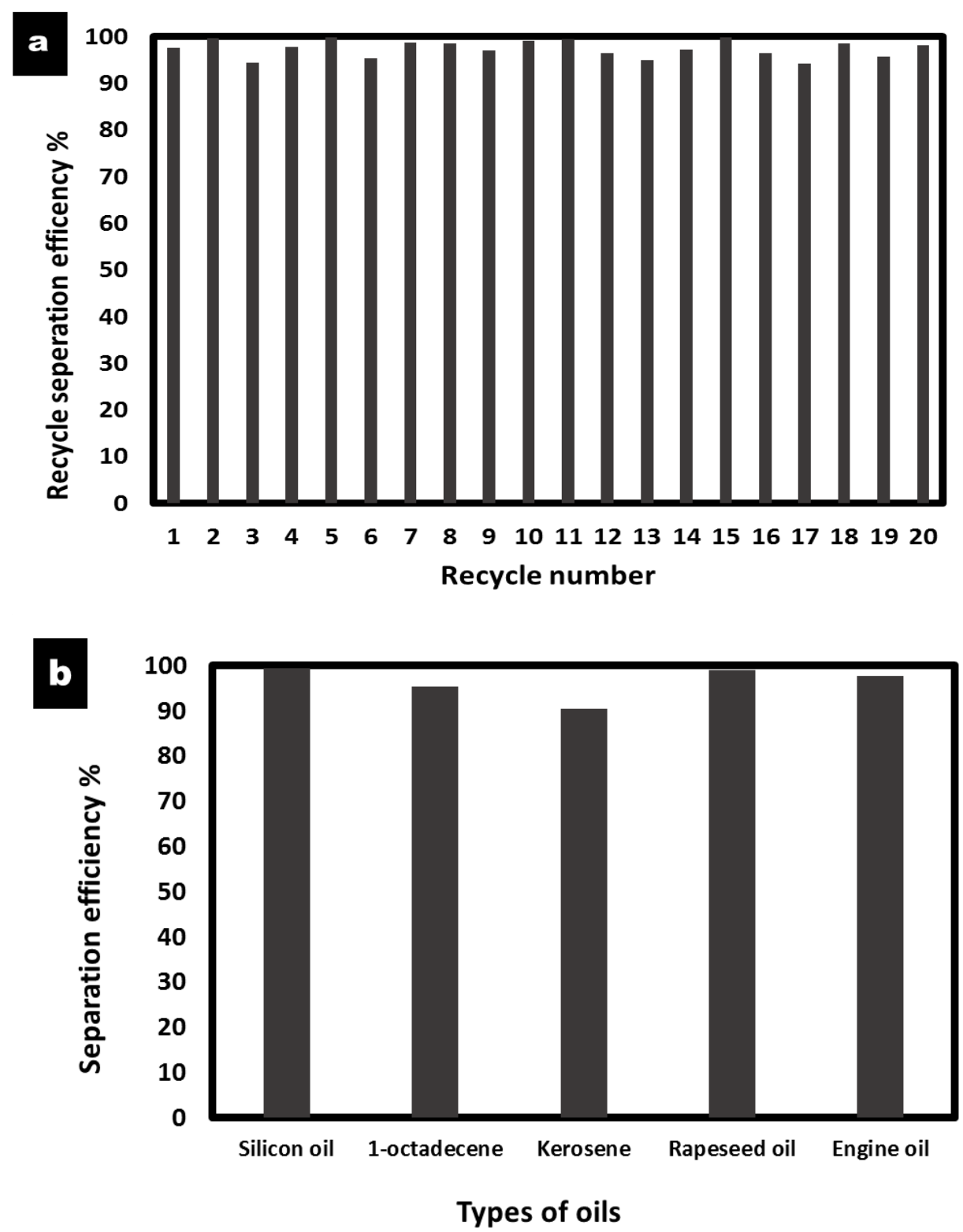

Figure 07 